Case Report

Relato de Caso

Victoria Hatzelis ${ }^{1}$

Thomas Murry²

Keywords

Laryngeal diseases/etiology

Laryngeal diseases/therapy

Vocal cords

Breathing exercises

Longitudinal studies

Descritores

Doenças da laringe/etiologia

Doenças da laringe/terapia Cordas vocais

Exercícios respiratórios Estudos longitudinais

Endereço para correspondência:

Thomas Murry, PhD

Department of Otolaryngology-Head and Neck Surgery

1305 York Avenue, 5th floor, 10021, New York (NY), USA.

E-mail: thm7001@med.cornell.edu

Received: 11/30/2011

Accepted: 2/6/2012

\section{Paradoxical vocal fold motion: respiratory retraining to manage long-term symptoms}

\author{
Movimento paradoxal de pregas vocais: reeducação \\ respiratória no monitoramento de sintomas de longo prazo
}

\begin{abstract}
Paradoxical vocal fold motion (PVFM) is a laryngeal disorder characterized by abnormal adduction of the vocal folds during respiration. It is caused by a multitude of etiologies and their interactions. In the current study, a 24-year-old female patient with a 12-year complaint of shortness of breath was diagnosed with paradoxical vocal fold motion following nasal endoscopy, spirometry testing and detailed case history analysis. She had no history or indication of laryngopharyngeal reflux or chronic cough. She performed respiratory retraining exercises three to four times daily for a period of four weeks, and continued daily exercises for two additional months as needed. After four weeks of treatment, abnormal vocal fold adduction continued to be seen on endoscopy and the patient was mildly symptomatic. One month post-treatment, there was no abnormal vocal fold adduction and the patient reported rare shortness of breath. At three months post-treatment, there was no abnormal vocal fold adduction and the patient no longer reported shortness of breath. She reported normal breathing with no symptoms one year later. The results suggest that non-pulmonary related shortness of breath treated with respiratory retraining can effectively eliminate dyspnea in patients with long term breathing difficulties caused by paradoxical vocal fold motion. Resolution may require treatment over an extended period of time.
\end{abstract}

\section{RESUMO}

O movimento paradoxal de pregas vocais (MPPV) é um distúrbio caracterizado por adução anormal das pregas vocais durante a respiração. Esse distúrbio é causado por uma série de causas e por suas interações. No presente estudo, uma paciente de 24 anos, do sexo feminino, com queixa de falta de ar há 12 anos teve o diagnóstico de movimento paradoxal de pregas vocais, a partir de dados de análise laríngea por nasoendoscopia, espirometria e avaliação clínica. A paciente não tinha histórico nem sinais de refluxo laringo-faríngico ou tosse crônica. A paciente foi submetida à reeducação respiratória, com treinamento de exercícios realizados de 3 a 4 vezes ao dia, por um período de quatro semanas, seguindo com um regime de exercícios diários por mais dois meses. Após quatro semanas de tratamento, a nasoendoscopia continuou indicando adução anormal das pregas vocais, porém em grau leve. Depois de um mês de tratamento, a movimentação das pregas vocais regularizou-se e a paciente referia frequência reduzida dos episódios de falta de ar. No acompanhamento de três meses após o tratamento, não foi observada alteração de adução de pregas vocais e nem referência à queixa de falta de ar. Somente no controle após um ano, a paciente mostrou-se livre de sintomas laríngeos e alteração respiratória. Os resultados sugerem que falta de ar sem alteração pulmonar, tratada por meio de reeducação respiratória fonoaudiológica, pode ser efetiva na eliminação da dispneia em pacientes com história crônica de dificuldades respiratórias causadas por movimento paradoxal de pregas vocais. A resolução do problema pode necessitar um tratamento prolongado.

Conflict of interests: None

(1) Department of Biobehavioral Sciences, Teachers College, Columbia University - New York (NY), United States.

(2) Department of Otolaryngology-Head and Neck Surgery, Weill Cornell Medical College, Cornell University - New York (NY), United States. 


\section{INTRODUCTION}

Paradoxical vocal fold motion (PVFM) is a laryngeal disorder in which excessive contraction of the adductor muscles causes the vocal folds to involuntarily adduct on inspiration ${ }^{(1)}$ or less commonly, on expiration ${ }^{(2)}$. Common indications of PVFM are shortness of breath and choking sensation ${ }^{(3)}$. Patients may also complain of hoarseness. PVFM has also been associated with chronic cough and reflux disease ${ }^{(4)}$. Although the majority of patients with PVFM are known to have normal pulmonary function, treatment of patients with PVFM often begins with pharmacological management of typical pulmonary symptoms such as cough and shortness of breath. This pharmacological treatment that often includes inhaled steroids usually does not resolve the patient's symptoms ${ }^{(5)}$. Triggers of PVFM may include one, or a combination of, the following: stress, exercise, extreme temperatures, airway irritants, aromas, odors or food products ${ }^{(4,5)}$.

Concomitant factors for PVFM in young active adults include significant social stressors, previous upper respiratory infection (URI) and a previous history of exercise induced asthma $^{(6,7)}$. While historically it was associated with psychiatric illness and factitious symptoms, more recent evidence supports that PVFM is associated with multiple etiologies and their interactions, including psychological, physiological and neurogenic factors ${ }^{(2)}$.

Diagnosis is based on case history and the visualization of the abnormal (paradoxical) movement of the vocal folds during flexible laryngoscopic examination and spirometry ${ }^{(3,4,8-10)}$. This paradoxical movement may be seen following an exercise task such as running, or it may occur spontaneously during restful breathing ${ }^{(7)}$.

Spirometry has been reported as an additional investigational tool in the diagnosis of PVFM. Spirometry offers information related to both inspiratory and expiratory events. The flow-volume loop pattern in PVFM is characterized by flattening or truncation of the inspiratory limb, compared to a U-shaped pattern in normal subjects ${ }^{(8)}$.

The flow-volume loop is uniquely helpful in the evaluation of upper airway obstruction. It has been found that individuals with a definite diagnosis of PVFM tended to have normal expiratory phases with attenuation in the inspiratory phase of the flow-volume loop, while those diagnosed with asthma presented in an opposite manner; that is, normal inspiratory phase and attenuated expiratory phase ${ }^{(11)}$.

Recently, it has been suggested that the diagnosis of PVFM should include both laryngoscopy and pulmonary function testing, though the sensitivity of the flow-volume loop may be low ${ }^{(12)}$.

Previous investigations have reported a range of incidence of PVFM of between 23-100\% when the inspiratory portion of the flow-volume loop shows an abnormal inspiratory pattern in asymptomatic patients with documented PVFM ${ }^{(11)}$.

Diagnosis of PVFM can be difficult when co morbidities such as asthma are present in the patient. However, with use of pulmonary function tests, pulmonary issues can be somewhat isolated from airway issues, especially if testing is done when patients are not on medications. The likelihood of improving diagnostic specificity increases when proper testing is carried out. Typical symptomatic presentations of PVFM, such as change of voice and stridor, are rarely seen in patients suffering from asthma, or they are reported as incidental to their primary problem of shortness of breath and thus often excluded in the diagnosis ${ }^{(9)}$.

Treatment options for PVFM generally begin with pharmacological management of commonly associated symptoms, including chronic cough and reflux disease. Various types of breathing exercises may be offered in conjunction with pharmacological management or separately. Often, no treatment options are offered secondary to inconclusive diagnosis. Occasionally, corticosteroids are erroneously offered as a treatment without resolution of symptoms.

The current investigation presents a case study of a 24-year-old female patient who initially presented with a history of shortness of breath and choking sensation unrelated to eating or drinking at approximately age 12 . After living with the problem and trying various medications over a ten-year period, she was diagnosed with PVFM. The objective of this study was to determine if respiratory retraining exercises alone would eliminate her breathing difficulties.

\section{CLINICAL CASE PRESENTATION}

\section{Subject}

A 24-year-old female patient who presented with a twelve-year history of periodic shortness of breath and choking sensation was diagnosed with PVFM at a University Medical Center in 2009. Diagnosis was made on the basis of clinical presentation following analysis of detailed case history, spirometric testing, and nasal endoscopy, in which airway reduction due to vocal fold adduction was observed by both authors to be greater than $50 \%$ on inspiration during quiet breathing. The patient was a non-smoker with no history of psychiatric illness or voice disorders. She reported that episodes of shortness of breath were frequently triggered by periods of life stress and extremely hot and humid temperatures, including while swimming indoors. Swimming or running outdoors was not triggers to shortness of breath.

The patient reported no symptoms nor was she ever diagnosed with chronic cough or laryngopharyngeal reflux, both commonly associated symptoms of $\mathrm{PVFM}^{(4)}$. The presence of laryngopharyngeal reflux was investigated using a self-administered, valid questionnaire, the Reflux Symptom Index $(\mathrm{RSI})^{(13)}$. Of a possible 45 points, the patient obtained a score of zero on the RSI. Further, no clinical signs of reflux such as inflammation or redness were present upon nasal endoscopy.

The patient's first episode of dyspnea was at age 12 while swimming indoors. The episodes continued intermittently while not swimming for several weeks and eventually became more common. At 13 years of age, the patient was evaluated by her physician for severe shortness of breath. The patient was under significant social stress in school, including maintaining a high academic record while participating in organized sports and an 
after-school club. A multitude of examinations were performed, including allergy, immunology, pulmonary function, chemistry and hematology tests; all results were within normal limits and no specific treatments were offered. Table 1 describes the tests performed and the results obtained from her previous medical histories.

Table 1. Previous medical tests and results conducted prior to diagnosis of paradoxical vocal fold motion when investigating patient's dyspnea symptoms

\begin{tabular}{ll}
\hline Test & Results \\
\hline $\begin{array}{l}\text { Chemistry } \\
\text { Glucose serum fasting }\end{array}$ & WNL \\
Triglycerides & WNL \\
Cholesterol & WNL \\
Cholesterol risk factor & Below average risk \\
Vitamin B12 & Not B12 deficient \\
Ferritin & Possibly iron deficient \\
sTSH & WNL \\
Hematology & \\
Hemoglobin & WNL \\
Hematocrit & WNL \\
RBC & WNL \\
RDW & WNL \\
WBC & WNL \\
Pulmonary function & \\
FVC (L) & 3.77 \\
Percentage of predicted value & 107 \\
FEV $/$ /FVC (\%) & 90 \\
Post-bronchodilation & No significant improvement \\
Allergy/lmmunology & Mild seasonal allergies to tree \\
Asthma & pollen, grass, ragweed \\
Echocardiogram and Color Doppler & Negative \\
& Normal cardiac structures \\
& and function \\
\hline & Normal valvular structures \\
\hline
\end{tabular}

Note: $\mathrm{WNL}=$ within normal limits; RBC = red blood cells; RDW = red cell distribution width; $\mathrm{WBC}=$ white blood cells; FVC = forced vital capacity; $\mathrm{FEV}_{1}=$ forced expiratory volume in one second

Following testing at age 13 and subsequent visits to various physicians, symptoms were ascribed to a combination of a habit and a stress related problem. Through appropriate testing, asthma, allergies and reflux were ruled out. Nonetheless, a corticosteroid inhaler was prescribed by the physician following persuasion from the patient's parent. It was ineffective in providing short- or long-term relief of symptoms and its use was eventually discontinued.

\section{Procedures}

The Free and Informed Consent Term was signed by the patient, thereby allowing the implementation and dissemination of research results. Following a light nasal decongestant, nasal endoscopy was used to examine vocal fold movement. After insertion and initial acclimatization to the endoscope, the patient breathed quietly for ten seconds through her nose, for ten seconds through her mouth, and then spoke the sentence "We see three green trees" two times. Observation of paradoxic motion was seen during both quiet breathing periods and following a spoken sentence. The patient then rhythmically tapped her feet for 15-30 seconds, and repeated the sequence of breathing quietly through her nose and mouth for ten seconds respectively. Rhythmic foot tapping was used to simulate activity without having to remove and re-insert the endoscope, as PVFM has been shown to be triggered by exercise ${ }^{(11)}$. The paradoxic motion continued following the foot tapping and the patient reported feeling short of breath. The entire procedure was repeated immediately following treatment and one month following treatment.

A diagnosis of paradoxical vocal fold motion was given after the video was reviewed. Significant airway closure was observed at rest, following sentence production and during and after the foot tapping. Spirometry was performed at initial diagnosis and at follow-up to objectively examine pulmonary function and airway obstruction. The expiratory phase was normal but a moderately flattened inspiratory loop was observed (Figure 1).

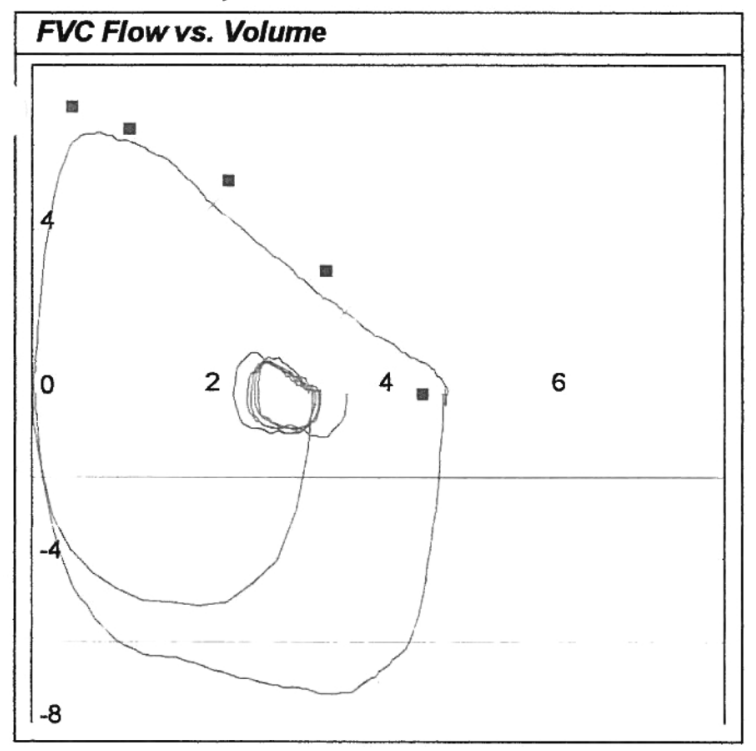

Figure 1. Spirometric data revealed a moderately flattened inspiratory loop at the initial diagnosis

Spirometry measures that were obtained and compared before and after treatment included $\mathrm{FEV}_{1} / \mathrm{FVC}$, the proportion of forced vital capacity exhaled in the first second compared to the forced vital capacity and the $\mathrm{FIV}_{0.5} / \mathrm{FIVC}$, the proportion of forced inspiratory capacity inhaled during the first 0.5 seconds compared to the total forced inspiratory capacity. These measures were previously found to be abnormal in patients with PVFM ${ }^{(4,8)}$.

Following diagnosis, the patient began respiratory retraining therapy. The second author (T.M.) conducted all therapy sessions and follow-ups. The patient performed the exercises daily for a one-month period, during which time she was seen for therapy once per week. At the end of one month she continued to perform the therapy techniques when she presented with 
symptoms. She reported that her symptoms resolved entirely after two months. Nasal endoscopy was repeated immediately after the one month of intensive treatment and at one- and three-months post-therapy.

The patient's symptoms were subjectively tracked using a severity rating scale from 1 to 5,1 representing no breathing difficulty and 5 representing severe breathing difficulty. She reported the number of training sessions she completed at each weekly treatment session. She also tracked her symptoms daily from time of initial diagnosis until three months following treatment.

Respiratory retraining exercises were based on the idea of augmenting the involvement of abdominal musculature during respiration, thus decreasing the demands and strain on the oropharyngeal muscles ${ }^{(10,14)}$. The following exercises were performed:

- Rhythmic breathing and walking. The patient walked at a slow pace while purposely relaxing chest and shoulder muscles by swinging the arms gently. She steadily exhaled concurrently with every second right step that she took, extending the abdominal muscles after each breath and consciously focusing on exhalation. She performed forced oral exhalation and passive nasal inhalation. The exhalation to inspiration ratio was approximately 1:3 seconds. To increase breathing resistance and since the patient experienced symptoms during exercise activities, slow walking was augmented to fast walking, followed by jogging and climbing stairs.

- Quiet rhythmic breathing and phonation. Patient forcefully exhaled for a count of one and inhaled for a count of three while sitting with shoulders and chest relaxed. She tapped her hand in order to keep a steady rhythm. Focus was on exhalation and abdominal extension so that passive inhalation could occur. To increase resistance, consonant phonation was added to exhalation phase for increasing lengths of time.

- Pulsed exhalation. Patient sniffed in rapidly through the nose and produced the sequence "ha" on a pulse of air. The sequence was produced with purposeful extension of abdominal muscles for as long as possible, followed by another nasal sniff.

- Abdominal focus in supine. Patient lay in supine position and placed a small book on her stomach. She consciously raised the book on inhalation and lowered the book on exhalation. After the breathing pattern was established, the book was removed and the patient continued abdominally-focused breathing. To increase resistance, the patient breathed through a straw while performing the exercise.

- Panting. Patient stood upright and took rapid, shallow inhalations mimicking panting. She focused on minimizing shoulder and upper body movement. She performed the exercise orally for 15 seconds, nasally for 15 seconds, and rested for 15 seconds, repeating the cycle four to five times.

Abdominal thrust. Patient produced a quick pulse of air through the mouth for one second and slowly inhaled through the nose for three seconds. Her hands were placed on her abdomen initially to retain the focus on abdominal breathing.
Exercises were performed three to four times daily to increase motor learning based on the principle of neuroplasticity of intensity, which posits that brain plasticity requires high intensity training ${ }^{(15)}$. As this was a long-standing problem for the patient, optimizing motor learning was an especially important consideration in the treatment procedures.

The patient participated in four sessions of respiratory retraining with the second author (T.M.) as described in the previous section. The duration of treatment was four weeks. Follow-up was conducted immediately following therapy, and one- and three-months post-therapy.

\section{Results}

Table 2 shows the results of the severity ratings. The patient's symptoms were subjectively rated daily using a scale of 1 to 5. At initial diagnosis, the patient rated her symptoms at a severity of 4.5. She continued to track her symptoms until the last follow-up visit.

Table 2. Severity of dyspnea symptoms associated with paradoxical vocal fold motion using a subjective rating between 1 (minimum) and 5 (maximum)

\begin{tabular}{lcc}
\hline Time & PVFM degree & Severity rating \\
\hline Diagnosis & $\begin{array}{c}>50 \% \text { vocal fold } \\
\text { adduction }\end{array}$ & 4.5 \\
End of treatment period & $\begin{array}{c}>50 \% \text { vocal fold } \\
\text { adduction }\end{array}$ & 2 \\
One-month post treatment & $\begin{array}{c}<50 \% \text { vocal fold } \\
\text { adduction }\end{array}$ & 1.5 \\
Three-months post treatment & $\begin{array}{c}<50 \% \text { vocal fold } \\
\text { adduction }\end{array}$ & 1 \\
One-year post treatment & & 1 \\
\hline
\end{tabular}

Note: PVFM = paradoxical vocal fold motion

Immediately following treatment, airway closure was observed during nasal endoscopy during quiet breathing. The patient reported to be mildly symptomatic, providing a subjective severity rating of 2 . She continued to perform respiratory retraining exercises to manage her symptoms.

One month post-treatment, there was no paradoxical vocal fold motion seen on endoscopy. The patient reported to occasionally present with very mild symptoms, providing a subjective rating of 1.5 . She continued the respiratory retraining therapy exercises when symptomatic.

Three months post-treatment, there was no vocal fold adductory motion was seen on endoscopy. The patient reported that she had not experienced any symptoms of either shortness of breath or choking sensation for over a month, providing a subjective rating of 1 . She no longer continued respiratory retraining therapy as she was no longer symptomatic.

One year post-treatment, the patient communicated with second author (T.M.) that she had not presented with any PVFM symptoms since their resolution the previous year and she rated her symptoms as a 1 .

Spirometric data before and immediately after treatment are 
shown in Table 3. The data suggest an above normal forced vital capacity (FVC) for her age and weight. Of note is the $\mathrm{FIV}_{0.5} l$ FIVC ratio which showed a small positive improvement. The $\mathrm{FEV}_{1} / \mathrm{FVC}$ remained stable.

Table 3. Spirometric data before and after respiratory retraining therapy

\begin{tabular}{lcc}
\hline Measure & Pre tx. value & Post tx. value \\
\hline FVC (L) & 4.82 & 4.89 \\
Percentage (\%) of predicted value & 107 & 109 \\
FIV $_{0.5} /$ FIVC ratio & 0.71 & 0.74 \\
FEV $_{1} /$ FVC (\%) & 0.79 & 0.79 \\
\hline
\end{tabular}

Change in $\mathrm{FIV}_{0.5} / \mathrm{FIVC}$ ratio $=0.03$

Note: FVC = forced vital capacity; FEV $_{1}=$ forced expiratory volume in the first second; $F I V C=$ forced inspiratory vital capacity; $\mathrm{FIV}_{0.5}=$ forced inspiratory volume in the first half second; Pre tx. $=$ pre-treatment; Post tx. $=$ post-treatment

\section{DISCUSSION}

As evidenced by this case study, paradoxical vocal fold motion is an elusive diagnosis that can be easily overlooked, misdiagnosed, or otherwise treated inappropriately. The multitude of symptoms, etiologies and their interactions associated with PVFM, including shortness of breath, chronic cough and reflux all exacerbate the difficulty of properly diagnosing the condition.

In cases in which the primary symptoms of PVFM are chronic cough and reflux, management is focused on elimination of reflux symptoms using medication such as proton pump inhibitors (PPIs) ${ }^{(4)}$ followed by respiratory retraining. However, as in the current case of PVFM without chronic cough or reflux, a program of multiple daily exercises focused on respiratory retraining alone was sufficient to completely eradicate a 12-year history of symptoms of dyspnea.

The patient continued to report mild symptoms of dyspnea one-month after the initial treatment program even though vocal fold adduction was not observed on endoscopy. The reasons for this are unclear, but it is possible that the long-standing history of the problem resulted in a psychological component of inducing symptoms in moments of stress, for example, reverting to previous breathing patterns. As the patient continued to practice the motor patterns learned in the one month of intensive treatment, she was able to entirely eliminate her breathing difficulties.

The inspiratory flow rate and ratios of inspiratory flow to vital capacity were not typical of data reported in previous studies $^{(9,11)}$. In this case study, the inspiratory flow loop was nearly normal and showed only minor flattening of the inspiratory segment. A possible explanation for this may be related to the subject who was an athlete and continued to be athletic has learned to control her inspiration when doing forceful tasks such as running or following the instructions during spirometry. Alternatively, as a result of numerous flow loop spirometry tests, the subject may have learned to control the inspiration during the test. Moreover, while many PVFM patients show a flattened inspiratory pattern with an abnormal FIV $_{0.5} /$ FIVC ratio, it has been reported in one study that as few as $28 \%$ of the PVFM patients had a truncated inspiratory flow loop ${ }^{(8)}$.
The length of time between the patient's initial evaluation of symptoms and actual diagnosis raises questions as to the general knowledge of PVFM in the greater medical community. Clearly, the use of scales such as the RSI, a thorough case history, proper nasal endoscopy and spirometry must be considered when the patient presents with episodic shortness of breath.

This case study of the patient's non-diagnosis for greater than ten years serves as evidence that PVFM can and does get overlooked and/or misdiagnosed. Healthcare professionals must take responsibility to rule out other conditions before writing off a complaint as being only stress-related, as was the initial diagnosis at the first visit when the subject was 13 years old. Further, ineffective medication coupled with the inability to control one's breathing can lead an affected psyche plagued by emotional distress and stress, as has been documented in the case of athletes ${ }^{(11)}$.

PVFM has historically been associated with psychogenic disorders and factitious symptoms ${ }^{(3,9)}$. It continues to pose challenges both in terms of diagnosis and treatment. Multiple possible contributions to a problem require careful diagnosis and treatment planning, as each case of PVFM is unique and deserves thorough consideration.

\section{FINAL COMMENTS}

Paradoxical vocal fold movement is a laryngeal disorder characterized by abnormal adduction of the vocal folds during respiration. It is caused by a multitude of etiologies and their interactions, and it is manifested by different symptoms, but primarily shortness of breath. The current case study presented a 24-year-old female patient with twelve year history of shortness of breath and choking sensation without chronic cough or reflux that was eventually diagnosed as PVFM. We investigated whether her symptoms could be treated solely by an intense respiratory retraining program since no history of asthma or reflux was present. Both subjective and objective improvements were documented following a one month course of therapy, with complete resolution of symptoms and abnormal vocal fold movement by the three month follow-up visit.

\section{REFERENCES}

1. Cukier-Blaj S, Bewley A, Aviv JE, Murry T. Paradoxical vocal fold motion: a sensory-motor laryngeal disorder. Laryngoscope. 2008;118(2):367-70.

2. Hicks M, Brugman SM, Katail R. Vocal cord dysfunction/paradoxical vocal fold motion. Prim Care. 2008;35(1):81-103.

3. Rogers JH, Stell PM. Paradoxical movement of the vocal cords as a cause of stridor. J Laryngol Otol. 1978;92(2):157-8.

4. Murry T, Tabaee A, Aviv JE. Respiratory retraining of refractory cough and laryngopharyngeal reflux in patients with paradoxical vocal fold motion disorder. Laryngoscope. 2004;114(8):1341-5.

5. Sandage MJ, Zelazny SK. Paradoxical vocal fold motion in children and adolescents. Lang Speech Hear Serv Sch. 2004;35(4):353-62.

6. Powell DM, Karanfilov BI, Beechler KB, Treole K, Trudeau MD, Forrest LA. Paradoxical vocal cord dysfunction in juveniles. Arch Otolaryngol Head Neck Surg. 2000;126(1):29-34.

7. Treole K, Trudeau MD, Forrest LA. Endoscopic and stroboscopic description of adults with paradoxical vocal fold dysfunction. J Voice. 1999;13(1):143-52. 
8. Morris MJ, Deal LE, Bean DR, Grbach VX, Morgan JA. Vocal cord dysfunction in patients with exertional dyspnea. Chest. 1999;116(6): 1676-82.

9. Vertigan AE, Gibson P, Theodoros DG, Winkworth AL. A review of voice and upper airway function in chronic cough and paradoxical vocal fold motion. Curr Opin Allergy Clin Immunol. 2007;7(1): 37-42.

10. Christopher KL, Wood, RP 2nd, Eckert RC, Blager FB, Raney RA, Souhrada JF. Vocal-cord dysfunction presenting as asthma. N Engl J Med. 1983;308(26):1566-70.

11. Newsham KR, Klaben BJ, Miller VJ, Saunders JE. Paradoxical vocalcord dysfunction: management in athletes. J Athl Train. 2002;37(3):3258 .
12. Christopher, KL. Morris, MJ. Vocal cord dysfunction, paradoxic vocal fold motion or laryngomalacia? Our understanding requires an interdisciplinary approach. Otolaryngol Clin North Am. 2010;43(1):4366.

13. Belafsky PC, Postma GN, Koufman JA. Validity and reliability of the reflux symptom index (RSI). J Voice. 2002;16(2):274-7.

14. Murry T, Sapienza C. The role of voice therapy in the management of paradoxical vocal fold motion, chronic cough, and laryngospasm. Otolaryngol Clin North Am. 2010;43(1):73-83, viii-ix.

15. Kleim JA, Jones TA. Principles of experience-dependent neural plasticity: implications for rehabilitation after brain damage. J Speech Lang Hear Res. 2008;51(1):S225-39. 